\title{
The physiological role of the unfolded protein response in plants
}

\author{
Adrian A. Moreno and Ariel Orellana \\ Núcleo Milenio en Biotecnología Celular, FONDAP Center for Genome Regulation, Centro de Biotecnología Vegetal, Facultad de Ciencias Biológicas, Universidad Andrés \\ Bello, Santiago, Chile.
}

\section{SUMMARY}

Unfolded protein response (UPR) is a signaling mechanism activated by misfolded protein accumulation in the endoplasmic reticulum. It is a widespread process that has been described in organisms ranging from yeasts to mammals. In recent years, our understanding of UPR signaling pathway in plants has advanced. Two transcription factors from Arabidopsis thaliana have been reported to function as the sensor/ transducer of this response (AtbZIP60 and AtbZIP28). They seem to be involved in both heat and biotic stress. Furthermore, overexpression of one of them (AtbZIP60) produces plants with a higher tolerance for salt stress, suggesting that this transcription factor may play a role in abiotic stress. Furthermore, some data suggest that crosstalk between genes involved in abiotic stress and UPR may also exist in plants. On the other hand, UPR is related to programmed cell death (PCD) in plants given that that triggering UPR results in induction of PCD-related genes. This article reviews the latest progress in understanding UPR signaling in plants and analyzes its relationship to key processes in plant physiology.

Key words: endoplasmic reticulum, plant, signaling, unfolded protein response.

\section{INTRODUCTION}

The endoplasmic reticulum (ER) is the organelle that hosts the synthesis and folding of membrane and secreted proteins. Given that the function of proteins depends on their threedimensional structure, their folding must be successful. In the ER, a complex orchestra of chaperones helps proteins acquire their final form (Trombetta and Parodi, 2003; Anelli and Sitia, 2008). However, in some cases protein folding fails and is degraded by endoplasmic reticulum-associated degradation machinery (ERAD) (Vembar and Brodsky, 2008). An increase in protein synthesis may disturb the folding process, resulting in accumulation of proteins that are not properly folded (Lu and Christopher, 2008). These misfolded or unfolded proteins tend to form aggregates, compromising ER activities, such as protein synthesis, protein folding and cell viability due to a decrease in essential proteins. To overcome this situation, a signaling pathway known as the unfolded protein response (UPR) is activated, synthesizing more chaperones and ERAD components to rescue misfolded proteins or eliminate those that cannot reach their proper form. If this proves impossible, the apoptosis pathway is activated and the cell eventually dies (Ron and Walter, 2007). The molecular mechanism underlying this physiological response has been studied extensively in yeast and mammals, and recent studies have focused on this signaling pathway in plants (Urade, 2007; Vitale and Boston, 2008; Urade, 2009). This article focuses on recent advances in plant research related to the molecular mechanism that supports the unfolded protein response and its impact on physiological plant processes.

\section{The UPR signaling mechanism in plants}

The first element related to UPR identified in plants was the inositol-required enzyme 1 (IRE1) in Arabidopsis thaliana (Koizumi et al., 2001) and rice (Oryza sativa) (Okushima et al.,
2002). IRE1's role is based on its ability to sense ER stress and effect unconventional splicing of HAC1 mRNA in yeast or $\mathrm{XBP1}$ in mammals. This process is based on IRE1 recognition of a highly conserved secondary structure in these mRNAs (Gonzalez et al., 1999; Yoshida et al., 2001). IRE1 RNAse activity in yeast has been well documented. In such species, the processing of HAC1 mRNA releases 252 nt (Cox and Walter, 1996). In mammals, $26 \mathrm{nt}$ are released when XBP1 is processed (Yoshida et al., 2001). Unconventional splicing is possible because IRE1 possess an endoribonuclease domain that becomes active after dimerization and autophosphorylation of the kinase domain also present in IRE1. The processing of the mRNA of HAC1 and XBP1 produces a transcription factor that regulates the expression of several ER-related genes that contain a sequence known as ER-response elements (ERSE and UPRE) in their promoters (Ron and Walter, 2007). Two genes with a high degree of homology to IRE1 from yeast and human were named AtIRE1-1 and AtIRE1-2 in Arabidopsis thaliana (Koizumi et al., 2001) and OsIRE1 in rice (Okushima et al., 2002), as shown in Figure 1. The N-terminal parts of the proteins encoded by these genes have the ability to sense the ER stress in heterologous systems like yeast. In addition, their kinase domain becomes autophosphorylated during in vitro assays. The subcellular localization of these proteins was analyzed and they were found to reside in the ER. However, no RNAse activity has been demonstrated for any of these proteins and no target mRNA has been identified. Recently, the analysis of insertional mutants for AtIRE1-1 and AtIRE1-2 was reported ( $\mathrm{Lu}$ and Christopher, 2008). The authors were unable to procure a homozygous mutant for the AtIRE1-1 gene and stated that they only obtained hemizygous plants after several generations, which led them to hypothesize that homozygous IRE1-1 plants are unviable. However, they did obtain a homozygous plant for the AtIRE1-2 gene, but it did not show an impaired response to ER stress triggered by tunicamycin or $\beta$-Mercaptoethanol measured by the induction of BiP2, bZIP60 
and several PDI mRNAs known to be upregulated during the unfolded protein response (Martinez and Chrispeels, 2003; Iwata and Koizumi, 2005b, Kamauchi et al., 2005). Thus, despite the early identification and description of some of its molecular functions, the role of IRE1 in plants seems to be a missing link in the context of UPR.

Another branch of UPR signaling that has been described in mammals is composed of a membrane anchored transcription factor known as activating transcription factor 6 (ATF6). This sensor resides in the ER until UPR is triggered. Once this occurs, the protein translocates to the Golgi apparatus due to the presence of two Golgi localization signals (GLS1 and GLS2), where it is processed by two serine proteases (S1P and S2P) (Ye et al., 2000). After these proteases act, the active transcription factor is released to regulate the expression of several ER-related genes in the nucleus (Ron and Walter, 2007). Several membrane-anchored transcription factors have been described in plants (Chen et al., 2008; Seo et al., 2008). The bZIP28, depicted in Figure 1 is an ER resident protein that is released from the ER to the nucleus under ER stress, a condition determined by GFP fusion experiments (Liu et al., 2007b). This protein also shares the S1P and S2P cleavage sites present in ATF6 from mammals, but only the effect of the S2P serine protease in releasing the active form of bZIP28 has been studied (Che et al., 2010). The transcription factor activity of bZIP28 has been demonstrated using promoters of ER chaperone genes such as $\mathrm{BiP}$ and $\mathrm{BiP} 3$ and a construction harboring hexamer of the ERSE and P-UPRE elements fused to the $35 \mathrm{~S}$ minimal promoter in transactivation assays (Tajima et al., 2008). In addition, Liu et al. (2007b) proved that plants overexpressing the active form of bZIP28 (which lacks the transmembrane domain located in the C-terminal part of the protein) have an enhanced expression of ER chaperone genes, such as BiP, BiP3, PDIL, CRT1 and CNX1. Interestingly, these plants show a delay in growth compared to wild-type plants, though no differences are observed when they reach maturity (Liu et al, 2007b).

A new branch unique to plants was discovered by Iwata and Koizumi (2005b) in Arabidopsis thaliana that involves a transcription factor known as AtbZIP60 (Fig. 1). The authors reported that the mRNA of AtbZIP60 is upregulated during ER stress and encodes a putative transmembrane domain located at the C-terminus of the protein, which should be removed in order to release the active transcription factor. Interestingly, they found that the active form of AtbZIP60 can activate its own promoter (Iwata and Koizumi, 2005b). Later, Tateda et al. (2008) described two tobacco orthologs of AtbZIP60, one from Nicotiana tabacum (NtbZIP60) and the other from Nicotiana benthamiana (NbbZIP60); however, only NtbZIP60 was shown to be up-regulated during ER stress. Furthermore, transactivation assays were used to show that, like AtbZIP60, NtbZIP60 needs to be processed in order to function as an active transcription factor in vivo. Iwata et al. (2008) recently suggested that AtbZIP60 is processed under ER stress conditions, since a polyclonal antibody against AtbZIP60 revealed two proteins when cells in culture were treated with tunicamycin or DTT. The analysis showed that the smaller protein corresponded to the cleaved form of AtbZIP60. In

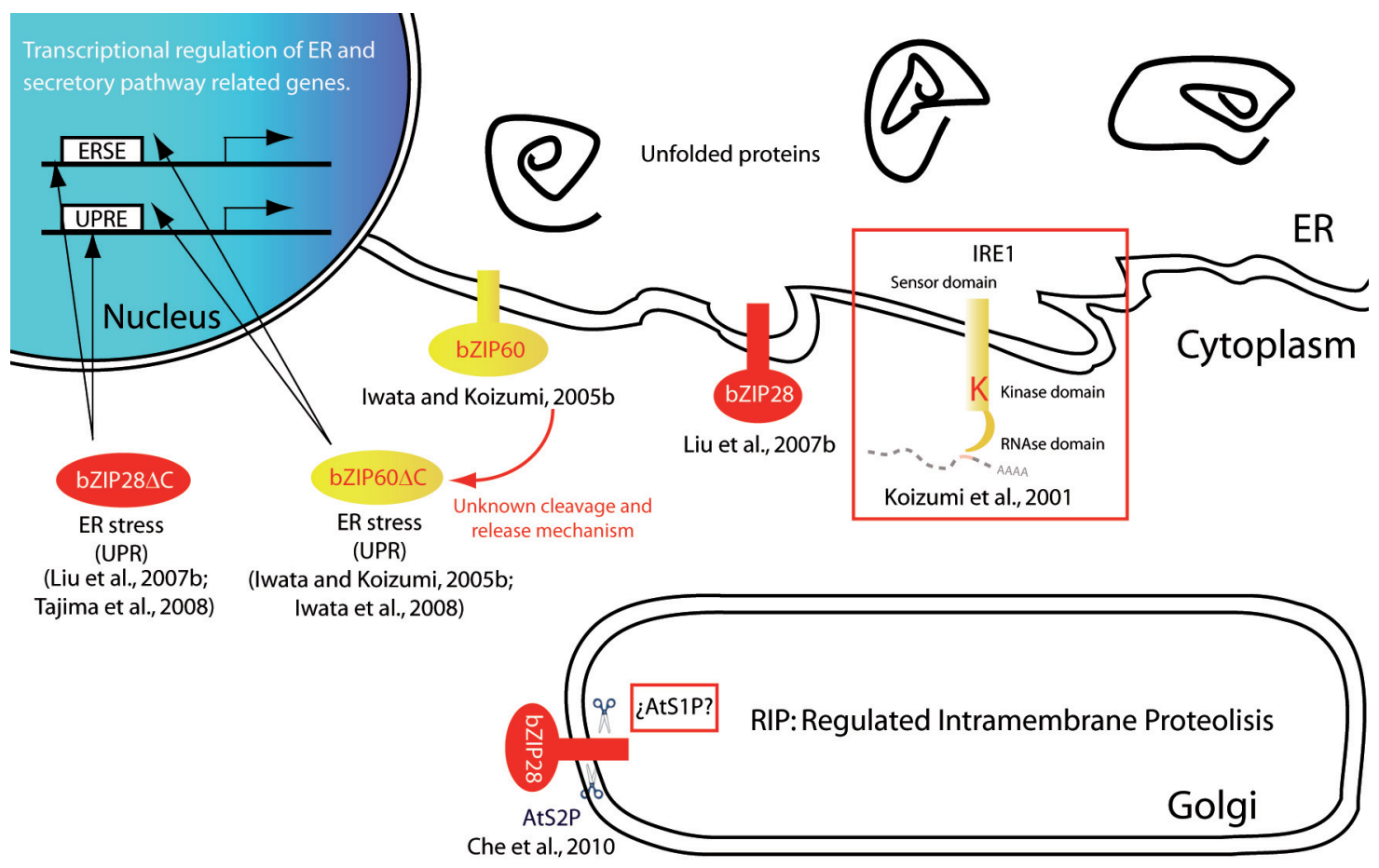

Figure 1. Model depicting different signaling branches of the UPR in plants: The diagram summarizes the major advances in identifying the components of UPR in plants. The authors' names and publication years are shown in reference to the articles in which the evidence was described. The red boxes indicate the processes related to the UPR signaling pathway that have not yet been proven. Although the IRE 1 component has not been related directly to the UPR in plants, it is included given its level of high conservation across eukaryotes and its crucial role in UPR. 
regard to the mechanism related to the processing of AtbZIP60, bioinformatics analyses revealed a lack of canonical S1P or S2P cleavage sites. Furthermore, the proteolytic processing of AtbZIP60 took place in S1P or S2P mutants (Iwata et al., 2008); therefore, it is likely that the mechanism associated with this processing is different from that of regulated intramembrane proteolysis (RIP) that is subjected to ATF6 or AtbZIP28.

Transcriptomic analyses of AtbZIP60 mutants showed no upregulation on several ER-related genes when compared to wild-type plants (Iwata et al., 2008), which suggests that the expression of several ER-related genes depends on AtbZIP60. Similar phenomena were reported by $\mathrm{Lu}$ and Christopher (2008) based on the analysis of the expression of several protein disulfide isomerases under ER stress conditions in wild-type and atbzip60 mutant plants. However, Iwata et al. (2008) also showed that some ER-related genes were induced, which suggests that some of them may be targets of other transcription factors such as AtbZIP28. This regulation by different transcription factors also is observed in mammals, where XBP1 and ATF6 are responsible for the regulation of different UPR-responding genes (Adachi et al., 2008; Yamamoto et al., 2008). Interestingly, in the absence of any treatment with chemicals that induce ER stress, both the processed and unprocessed forms of AtbZIP60 were detected in anthers (Iwata et al., 2008), suggesting that this organ may have an endogenous activation of this pathway.

Physiological role of the UPR

After the identification of UPR as a signaling process, the relationship between it and several human diseases and other physiological processes was evident (for reviews, see Herbert and Molinari, 2007; Lee and Glimcher, 2009; Naidoo, 2009). It is commonly accepted that the activation of this response is necessary to maintain the homeostasis of several cellular processes as it has been shown to occur during the B-cells differentiation to plasma cells (Iwakoshi et al., 2003). The unfolded protein response has recently been associated with plant resistance to heat stress and pathogen attacks, which indicates that UPR plays a role in these processes. The presence of AtbZIP28 seems to be important during heat stress because a lack of this gene affects plants susceptibility to acute heat stress (Gao et al., 2008). Indeed, when mutant plants on AtbZIP28 were exposed to $42{ }^{\circ} \mathrm{C}$ for 2 hours, they developed a clearly chlorotical phenotype that could be rescued by the insertion of a transgene encoding YFP-AtbZIP28 under the control of its own promoter. This confirms the importance of AtbZIP28 in heat stress and that the observed phenotype is the result of a lack of AtbZIP28 and not other events related to the T-DNA insertion (Fig. 2A).

In regard to biotic stress, recent evidence derived from the work of Tateda et al. (2008) showed that N. benthamiana plants, which were silenced for NbbZIP60 expression, were more susceptible to infection with Pseudomonas cichorii (Fig. 2B). Furthermore, they also showed that spermine, a polyamine involved in the hypersensitive response (HR) in tobacco (Takahashi et al., 2004), produced an increase in NbbZIP60 mRNA levels. Previously, Lee et al. (2006) had shown that a bZIP transcription factor from pepper called CabZIP1 was upregulated during the attack of Xanthomonas campestris pv. Vesicatoria or Pseudomonas fluorescens pathogens. Interestingly, CabZIP1 share a high degree of homology with AtbZIP60; unfortunately, it has not yet been shown whether this transcription factor is upregulated during ER stress.

Lee at al. (2006) also showed that the overexpression of CabZIP1 in Arabidopsis thaliana confers resistance to abiotic stresses such as salinity, drought and osmotic stress. In addition, these plants are resistant to biotic stress and high concentrations of ABA. Moreover, Arabidopsis thaliana plants that overexpress AtbZIP60 are also more tolerant to salt stress (Fujita et al., 2007). This finding suggests that UPR plays a role in providing greater tolerance to salt stress in plants. It also
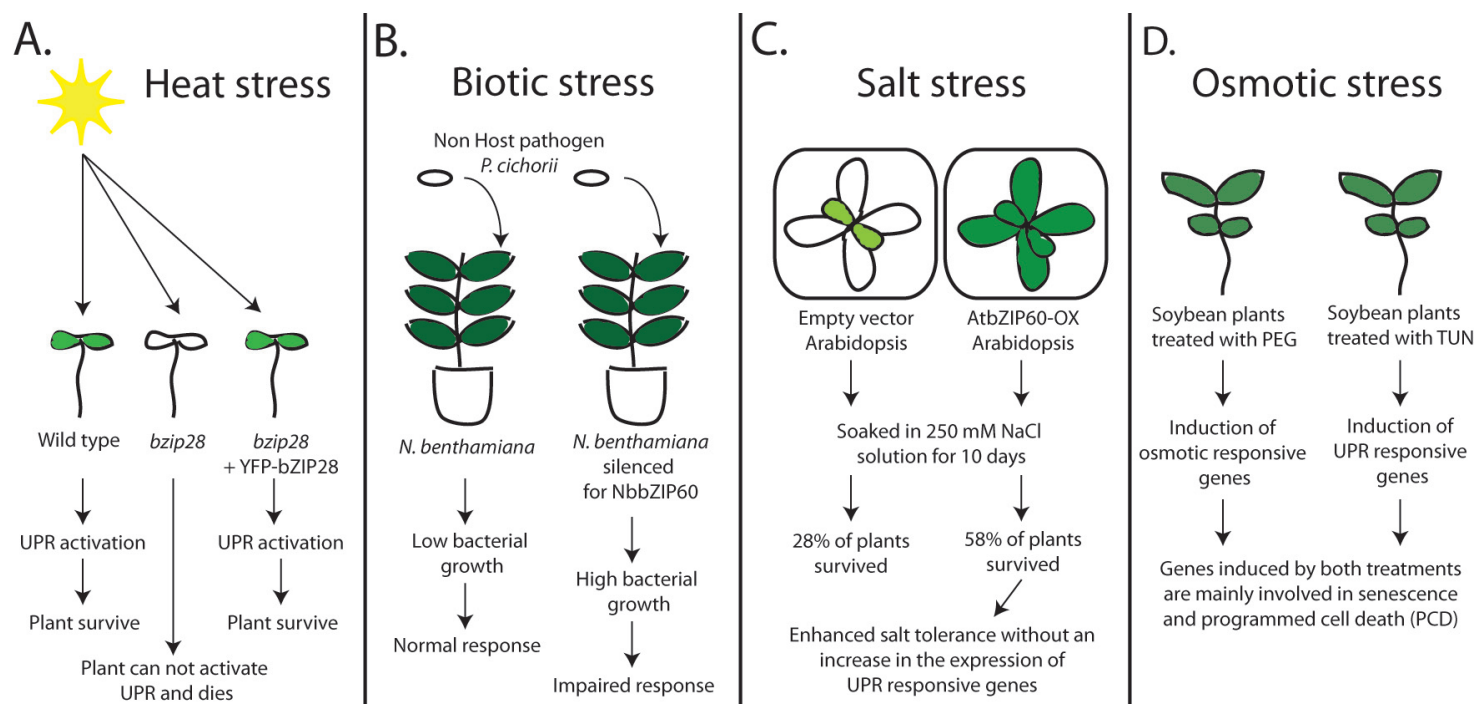

Figure 2. Schematic representation of the involvement of UPR in abiotic and biotic stresses: The role of UPR in plants has been analyzed using mutant and transgenic plants. The conclusions of these experiments, described throughout the text, are that UPR plays a role in heat $(\mathbf{A})$, biotic $(\mathbf{B})$, osmotic (C) and salt (D) stresses. 
reveals an intimate relationship between the UPR signaling and salt stress (Fig. 2C). Liu et al. (2007a) describe one candidate for this new pathway, showing that the transcription factor AtbZIP17 resides in the ER and is processed by S1P under high salt stress, releasing the active transcription factor in the same manner as occurs with AtbZIP28. However, the active form of AtbZIP17 regulates the expression of genes related to salt stress such as ATHB-7. Interestingly, AtbZIP28 is not processed under salt stress (Liu et al., 2007b). A recent report supported the hypothesis that UPR plays a role in salt stress, showing that Arabidopsis mutant plants lacking an ERlocalized zinc transporter (ZTP9) were more sensitive to this type of stress (Wang et al., 2010). Remarkably, the transcript of AtbZIP60 and AtBiP2 did not accumulate in ztp9 mutant plants under salt stress as had been observed in wild-type plants. This data suggests that zinc homeostasis could be a new component in UPR signaling under salt stress.

In regard to drought tolerance and its relationship to ER stress, Valente et al. (2009) showed that soybean plants overexpressing $\mathrm{BiP}$ are more tolerant to drought, though the mechanism associated with this phenomenon is as yet unknown. Irsigler et al. (2007) performed expression profile analyses of soybean plants treated with tunicamycin/AZT or PEG, suggesting that there is a link between UPR and the osmotic stress pathway (Fig. 2D). Their research also demonstrated the involvement of a less-explored component of UPR in plants, programmed cell death (PCD) triggered by ER stress (Crosti et al., 2001; Zuppini et al., 2004; Iwata and Koizumi, 2005a). This conclusion arises from the observation that two of the genes upregulated by the two stresses, both of which are annotated as asparagine rich (N-rich) proteins, do not belong to the ER chaperones or ER-related genes. As Costa et al. (2008) later demonstrated, they are actually related to PCD. Something similar was found in the case of Hsr203J in BY-2 tobacco cells (Iwata and Koizumi, 2005a), namely, a gene associated with cell death that is upregulated in later stages of ER stress instead of BiP and PDI chaperones. This gene also has been involved in cell death triggered by the hypersensitive response (HR) in tobacco, a process that is triggered in plant tissues that are under pathogen attack. Another gene involved in plant PCD is Bax Inhibitor 1 from Arabidopsis thaliana (AtBI-1), which is upregulated during the early stages of activation by UPR (Kamauchi et al., 2005; Wanatabe and Lam, 2008). The promoter of AtBI-1 contains a canonical cis-acting response element (ERSE-like) related to UPR (Kamauchi et al., 2005), while the genes involved in PCD mentioned above do not. Thus, the presence of this element may explain the early induction of AtBI-1. One of the consequences of the early expression of AtBI-1 is the cytoprotective effect that this gene provides to plants under ER stress. It is more evident in plants lacking this gene, since they exhibit an increase in the triggering of programmed cell death when they are treated with tunicamycin (Wanatabe and Lam, 2008). Williams et al. (2010) recently reported another gene involved in cytoprotection, showing that AtBAG-7, a Bcl-2-associated athanogene (BAG) family protein member, is localized in the ER and interacts with BiP2. Interestingly, AtBAG-7 null mutants exhibit enhanced susceptibility to heat and cold stress. Furthermore, an accelerated cell death phenotype is observed in these mutant plants when they are treated with chemicals that induce UPR. It is important to note that the AtBAG-7 transcript is not accumulated during UPR and its promoter lacks canonical ERSE-like elements suggesting another kind of regulation under ER stress conditions. ER chaperones has been also involved in PCD. Recently, Ondzighi et al. (2008) demonstrated that PDI5 is necessary during seed development. Specifically it delays PCD in endothelial cells by interacting with three different Cysteine proteases in their route from the ER to the vacuole. In addition, mutants lacking the PDI5 gene show premature initiation of PCD during embryogenesis. Since PDI5 is upregulated by UPR (Lu and Christopher, 2008) and given the importance of this protein during embryogenesis, it is likely that this signaling pathway is activated during seed development. The occurrence of UPR also has been reported in several maize mutants such as Mucronate, Opaque2, De*-B30, floury-1 and floury-2 (Coleman et al., 1995; Kim et al., 2004; Kim et al., 2006; Holding et al., 2007). For example, floury-2 exhibited a modified starchy endosperm and subsequent experiments showed that a mutation in the signal peptide of an $\alpha$-zein, which blocks cleavage and keeps this protein anchored to the membrane of protein bodies, was responsible for the observed phenotype (Coleman et al., 1995; Gillikin et al., 1997). In fact, the synthesis of this mutated form of $\alpha$-zein triggers ER stress since a high expression of the BiP gene can be observed both in floury-2 and transgenic maize that harbor the mutated form of this $\alpha$-zein. But in addition to these early observations, an interesting phenomena was described by Shank et al. (2001), who observed a modification in the synthesis of lipids in the floury-2 maize due to the upregulation of four enzymes involved in lipids synthesis -diacylglycerol (DG) kinase, phosphatidylinositol (PI) 4-phosphate 5-kinase, cholinephosphate cytidylyltransferase (CCT) and PI 4-kinase-. In addition, they found a significant increase in the incorporation of radiolabeled acetate into phospholipids of soybean culture cells treated with tunicamycin, suggesting that activation of the UPR is linked to an increase in phospholipid biosynthesis. Mouse embryo fibroblast culture cells transfected with the active form of XBP1 showed an enhanced activity of CCT (Sriburi et al., 2004). This result is in agreement with the fact that the CCT activity in protein bodies of floury-2 maize also increases when UPR is activated (Shank et al., 2001). Furthermore, Arabidopsis thaliana culture cells treated with salycilic acid leads to the upregulation of the ER stress markers BiP3 and PDI as well as the PI 4-kinase (Krinke et al., 2007), enzyme that is also activated in floury-2.

In regard to seed development, the idea of an "anticipatory" UPR seems convenient due to the high synthesis of storage proteins during certain periods of embryo and endosperm development. Houston et al. (2005) showed that $\mathrm{BiP}$ and ZmPDIL5-1 proteins accumulate differentially in floury-2 maize following the onset of zein protein accumulation 15 days after pollination (DAP) and Shank et al. (2001) reported an increase in CCT enzyme activity 16 days after pollination in this mutant. Unfortunately, wild-type maize shows no differential accumulation of BiP or ZmPDIL5-1 and CCT activity appears to drop off 10 to 16 days after pollination. Therefore, despite the suggestion that UPR may be involved in seed development, additional support for this hypothesis is needed.

Another proposed physiological role for the "anticipatory" UPR could emerge during pathogen attacks where systemic acquired resistance (SAR) is triggered by the plant as a defense mechanism. This leads to the synthesis of salycilic acid, which activates a signaling cascade that includes the 
synthesis of proteins made in the ER, such as pathogenesisrelated proteins (PR), as well as other kinds of proteins needed during this response. However, only indirect evidence related to this process has been gathered to date, and all the data relies on measuring the differential accumulation of several ER chaperones and ER-related genes during SAR in Arabidopsis thaliana and Nicotiana tabacum (Jelitto-Van Dooren et al., 1999; Wang et al., 2005). The roles of elements such as transcription factors in the activation of UPR remain to be analyzed.

\section{Future perspectives}

Significant progress has been made in understanding the UPR signaling pathway in plants. However, much has yet to be learned about UPR branches described in other organisms. One of the main questions has to do with the branch described in mammals, which involves the interferon-induced dsRNAactivated kinase-related protein (PERK). Under ER stress conditions, this protein can phosphorylate the eIF2 $\alpha$, inducing a general attenuation of protein translation (Sood et al., 2000; Harding et al., 2000). This event also enhances the synthesis of ATF4, another transcription factor that is repressed under normal conditions due the presence of upstream ORFs in its mRNA (Vattem and Wek, 2004). The main role of ATF4 is related to upregulating the CHOP gene, which acts in the programmed cell death pathway (Ron and Walter, 2007). In plants, searches for sequences related to PERK in several databases have failed. It is possible that this pathway is not present in plants; however, Kamauchi et al. (2005) showed that Arabidopsis thaliana possess an ortholog of $\mathrm{P} 58^{\mathrm{IPK}}$ that is induced during ER stress. Moreover, the upregulation of this gene attenuates the phosphorylation of eIF2 $\alpha$ in a similar manner to what has been described in mammals (Yan et al., 2002). Therefore, it is possible that a functional ortholog of PERK exists in plants.

In regard to other signaling pathways involving protein kinases that are associated with ER stress, a $G_{\beta}$ protein from Arabidopsis thaliana recently was found to be involved in the susceptibility to cell death in tissues exposed to tunicamycin (Wang et al., 2007). The authors observed that leaves from mutants in this gene are less susceptible to cell death after tunicamycin infiltration. Subcellular analyses of this protein indicated that it is located at the ER, though the mechanism behind cell death attenuation remains unclear.

It is important to mention that UPR research in plants has yielded a fair amount of evidence related to the genes that participate in the UPR signaling cascade. However, some issues have yet to be addressed, such as the real function of IRE1-1 and IRE1-2 in Arabidopsis thaliana and the means by which AtbZIP60 senses ER stress and is released from the ER membrane. Finally, one of the questions that remain regarding SAR is whether the branches of UPR described thus far are involved in this anticipatory response. Though further research is required to provide answers these questions, it is clear that a great deal of challenging work remains to be done on UPR in plants.

\section{ACKNOWLEDGMENTS}

This work was supported by Fondecyt 1070379, PCB-MN P06-065-F and PFB-16. AM is supported by a CONICYT-Chile Doctoral fellowship.

\section{REFERENCES}

ADACHI Y, YAMAMOTO K, OKADA T, YOSHIDA H, HARADA A, MORI K. (2008) ATF6 is a transcription factor specializing in the regulation of quality control proteins in the endoplasmic reticulum. Cell Struct Funct 33: 75-89.

ANELLI T, SITIA R. (2008) Protein quality control in the early secretory pathway. EMBO J 27: 315-327.

CHE P, BUSSELL JD, ZHOU W, ESTAVILLO GM, POGSON BJ, SMITH SM. (2010) Signaling from the endoplasmic reticulum activates brassinosteroid signaling and promotes acclimation to stress in Arabidopsis. Sci Signal. 3: ra69.

CHEN YN, SLABAUGH E, BRANDIZZI F. (2008) Membrane-tethered transcription factors in Arabidopsis thaliana: novel regulators in stress response and development. Curr Opin Plant Biol 11: 695-701.

COLEMAN CE, LOPES MA, GILLIKIN JW, BOSTON RS, LARKINS BA (1995) A defective signal peptide in the maize high-lysine mutant floury 2. Proc Natl Acad Sci, USA 92: 6828-6831.

COSTA MD, REIS PA, VALENTE MA, IRSIGLER AS, CARVALHO CM, LOUREIRO ME, ARAGAO FJ, BOSTON RS, FIETTO LG, FONTES EP. (2008) A new branch of endoplasmic reticulum stress signaling and the osmotic signal converge on plant-specific asparagine-rich proteins to promote cell death. J Biol Chem 283: 20209-20219.

COX JS, WALTER P. (1996) A novel mechanism for regulating activity of a transcription factor that controls the unfolded protein response. Cell 87: 391-404.

CROSTI P, MALERBA M, BIANCHETTI R. (2001) Tunicamycin and Brefeldin A induce in plant cells a programmed cell death showing apoptotic features. Protoplasma 216: 31-38.

FUJITA M, MIZUKADO S, FUJITA Y, ICHIKAWA T, NAKAZAWA M, SEKI M, MATSUI M, YAMAGUCHI-SHINOZAKI K, SHINOZAKI K. (2007) Identification of stress-tolerance-related transcription-factor genes via mini-scale Full-length cDNA Over-eXpressor (FOX) gene hunting system. Biochem Biophys Res Commun 364: 250-257.

GAO H, BRANDIZZI F, BENNING C, LARKIN RM. (2008) A membranetethered transcription factor defines a branch of the heat stress response in Arabidopsis thaliana. Proc Natl Acad Sci, USA 105: 16398-16403.

GILLIKIN JW, ZHANG F, COLEMAN CE, BASS HW, LARKINS BA, BOSTON RS. (1997) A defective signal peptide tethers the floury-2 zein to the endoplasmic reticulum membrane. Plant Physiol 114: 345-352.

GONZALEZ, T.N., SIDRAUSKI, C., DORFLER, S., AND WALTER, P. (1999). Mechanism of non-spliceosomal mRNA splicing in the unfolded protein response pathway. EMBO J 18, 3119-3132.

HARDING HP, ZHANG Y, BERTOLOTTI A, ZENG H, RON D. (2000) Perk is essential for translational regulation and cell survival during the unfolded protein response. Mol Cell 5: 897-904.

HERBERT DN, MOLINARI M. (2007) In and out of the ER: protein folding, quality control, degradation, and related human diseases. Physiol Rev 87: 1377-1408.

HETZ C, GLIMCHER LH. (2009) Fine-tuning of the unfolded protein response: Assembling the IRE1alpha interactome. Mol Cell 35: 551-561.

HOLDING DR, OTEGUI MS, LI B, MEELY RB, DAM T, HUNTER BG, JUNG R, LARKINS BA. (2007) The maize floury1 gene encodes a novel endoplasmic reticulum protein involved in zein protein body formation. Plant Cell 19: 2569-2582.

HOUSTON NL, FAN C, XIANG JQ, SCHULZE JM, JUNG R, BOSTON RS (2005) Phylogenetic analyses identify 10 classes of the protein disulfide isomerase family in plants, including single-domain protein disulfide isomerase-related proteins. Plant Physiol 137: 762-778.

IRSIGLER AS, COSTA MD, ZHANG P, REIS PA, DEWEY RE, BOSTON RS, FONTES EP. (2007) Expression profiling on soybean leaves reveals integration of ER- and osmotic-stress pathways. BMC Genomics 8: 431.

IWAKOSHI NN, LEE AH, GLIMCHER LH. (2003) The X-box binding protein-1 transcription factor is required for plasma cell differentiation and the unfolded protein response. Immunol Rev 194: 29-38.

IWATA Y, KOIZUMI N. (2005a) Unfolded protein response followed by induction of cell death in cultured tobacco cells treated with tunicamycin. Planta 220: 804-807.

IWATA Y, KOIZUMI N. (2005b) An Arabidopsis transcription factor, AtbZIP60, regulates the endoplasmic reticulum stress response in a manner unique to plants. Proc Natl Acad Sci, USA 102: 5280-5285.

IWATA Y, FEDOROFF NV, KOIZUMI N. (2008) Arabidopsis bZIP60 is a proteolysis-activated transcription factor involved in the endoplasmic reticulum stress response. Plant Cell 20: 3107-3121. 
JELITTO-VAN DOOREN EP, VIDAL S, DENECKE J. (1999) Anticipating endoplasmic reticulum stress. A novel early response before pathogenesis-related gene induction. Plant Cell 11: 1935-1944.

KAMAUCHI S, NAKATANI H, NAKANO C, URADE R. (2005) Gene expression in response to endoplasmic reticulum stress in Arabidopsis thaliana. FEBS J 272: 3461-3476.

KIM CS, HUNTER BG, KRAFT J, BOSTON RS, YANS S, JUNG R, LARKINS BA. (2004) A defective signal peptide in a 19-kD alpha-zein protein causes the unfolded protein response and an opaque endosperm phenotype in the maize De*-B30 mutant. Plant Physiol 134: 380-387.

KIM CS, GIBBON BC, GILLIKIN JW, LARKINS BA, BOSTON RS, JUNG R. (2006) The maize Mucronate mutation is a deletion in the $16-\mathrm{kDa}$ gamma-zein gene that induces the unfolded protein response. Plant J 48: $440-451$.

KOIZUMI N, MARTINEZ IM, KIMATA Y, KOHNO K, SANO H, CHRISPEELS MJ. (2001) Molecular characterization of two Arabidopsis Ire1 homologs, endoplasmic reticulum-located transmembrane protein kinases. Plant Physiol 127: 949-962.

KRINKE O, RUELLAND E, VALENTOVA O, VERGNOLLE C, RENOU JP, TACONNAT L, FLEMR M, BURKETOVA L, ZACHOWSKI A. (2007) Phosphatidylinositol 4-kinase activation is an early response to salicylic acid in Arabidopsis suspension cells. Plant Physiol 144: 1347-1359.

LEE SC, CHOI HW, HWANG IS, CHOI DU S, HWANG BK. (2006) Functional roles of the pepper pathogen-induced bZIP transcription factor, CAbZIP1, in enhanced resistance to pathogen infection and environmental stresses. Planta 224: 1209-1225.

LEE AH, GLIMCHER LH. (2009) Intersection of the unfolded protein response and hepatic lipid metabolism. Cell Mol Life Sci 66: 2835-2850.

LIU JX, SRIVASTAVA R, CHE P, HOWELL SH. (2007a) Salt stress responses in Arabidopsis utilize a signal transduction pathway related to endoplasmic reticulum stress signaling. Plant J 51:897-909.

LIU JX, SRIVASTAVA R, CHE P, HOWELL SH. (2007b) An endoplasmic reticulum stress response in Arabidopsis is mediated by proteolytic processing and nuclear relocation of a membrane-associated transcription factor, bZIP28. Plant Cell 19: 4111-4119.

LU DP, CHRISTOPHER DA. (2008) Endoplasmic reticulum stress activates the expression of a sub-group of protein disulfide isomerase genes and AtbZIP60 modulates the response in Arabidopsis thaliana. Mol Genet Genomics 280: 199-210.

LU DP, CHRISTOPHER DA. (2008) Light enhances the unfolded protein response as measured by BiP2 gene expression and the secretory GFP2SC marker in Arabidopsis. Physiol Plant, 134: 360-368.

MARTINEZ IM, CHRISPEELS MJ. (2003) Genomic analysis of the unfolded protein response in Arabidopsis shows its connection to important cellular processes. Plant Cell 15: 561-576.

NAIDOO N. (2009) The endoplasmic reticulum stress response and aging. Rev Neurosci 20: 23-37.

ONDZIGHI CA, CHRISTOPHER DA, CHO EJ, CHANG SC, STAEHELIN LA. (2008) Arabidopsis protein disulfide isomerase-5 inhibits cysteine proteases during trafficking to vacuoles before programmed cell death of the endothelium in developing seeds. Plant Cell, 20: 2205-20.

OKUSHIMA Y, KOIZUMI N, YAMAGUCHI Y, KIMATA Y, KOHNO K, SANO H. (2002) Isolation and characterization of a putative transducer of endoplasmic reticulum stress in Oryza sativa. Plant Cell Physiol 43: $532-539$.

RON D, WALTER P. (2007) Signal integration in the endoplasmic reticulum unfolded protein response. Nat Rev Mol Cell Biol 8: 519-529.

SEO PJ, KIM SG, PARK CM. (2008) Membrane-bound transcription factors in plants. Trends Plant Sci 13: 550-556.

SHANK KJ, SU P, BRGLEZ I, BOSS WF, DEWEY RE, BOSTON RS. (2001) Induction of lipid metabolic enzymes during the endoplasmic reticulum stress response in plants. Plant Physiol 126: 267-277.

SOOD R, PORTER AC, MA K, QUILLIAM LA, WEK RC. (2000) Pancreatic eukaryotic initiation factor-2alpha kinase (PEK) homologues in humans, Drosophila melanogaster and Caenorhabditis elegans that mediate translational control in response to endoplasmic reticulum stress Biochem J 346: 281-293.
SRIBURI R, JACKOWSKI S, MORI K, BREWER JW. (2004) XBP1: a link between the unfolded protein response, lipid biosynthesis, and biogenesis of the endoplasmic reticulum. J Cell Biol 167: 35-41.

TAJIMA H, IWATA Y, IWANO M, TAKAYAMA S, KOIZUMI N. (2008) Identification of an Arabidopsis transmembrane bZIP transcription factor involved in the endoplasmic reticulum stress response. Biochem Biophys Res Commun 374: 242-247.

TAKAHASHI Y, UEHARA Y, BERBERICH T, ITO A, SAITOH H, MIYAZAKI A, TERAUCHI R, KUSANO T. (2004) A subset of hypersensitive response marker genes, including HSR203J, is the downstream target of a spermine signal transduction pathway in tobacco. Plant J 40: 586-595.

TATEDA C, OZAKI R, ONODERA Y, TAKAHASHI Y, YAMAGUCHI K, BERBERICH T, KOIZUMI N, KUSANO T. (2008) NtbZIP60, an endoplasmic reticulum-localized transcription factor, plays a role in the defense response against bacterial pathogens in Nicotiana tabacum. J Plant Res 121: 603-611.

TROMBETTA ES, PARODI AJ. (2003) Quality control and protein folding in the secretory pathway. Annu Rev Cell Dev Biol 19: 649-676.

URADE R. (2007) Cellular response to unfolded proteins in the endoplasmic reticulum of plants. FEBS J 274: 1152-1171.

URADE R. (2009) The endoplasmic reticulum stress signaling pathways in plants. BioFactors, 35: 326-331

VALENTE MA, FARIA JA, SOARES-RAMOS JR, REIS PA, PINHEIRO GL, PIOVESAN ND, MORAIS AT, MENEZES CC, CANO MA, FIETTO LG, LOUREIRO ME, ARAGAO FJ, FONTES EP. (2009) The ER luminal binding protein $(\mathrm{BiP})$ mediates an increase in drought tolerance in soybean and delays drought-induced leaf senescence in soybean and tobacco. J Exp Bot 60: 533-546.

VATTEM KM, WEK RC. (2004) Reinitiation involving upstream ORFs regulates ATF4 mRNA translation in mammalian cells. Proc Natl Acad Sci, USA 101: 11269-11274.

VEMBAR SS, BRODSKY JL. (2008) One step at a time: endoplasmic reticulum-associated degradation. Nat Rev Mol Cell Biol 9: 944-957.

VITALE A, BOSTON RS. (2008) Endoplasmic reticulum quality control and the unfolded protein response: insights from plants. Traffic 9: 1581-1588.

WANG D, WEAVER ND, KESARWANI M, DONG X. (2005) Induction of protein secretory pathway is required for systemic acquired resistance. Science 308: 1036-1040.

WANG S, NARENDRA S, FEDOROFF N. (2007) Heterotrimeric G protein signaling in the Arabidopsis unfolded protein response. Proc Natl Acad Sci, USA 104: 3817-3822.

WANG M, XU Q, YU J, YUAN M. (2010) The putative Arabidopsis zinc transporter ZTP29 is involved in the response to salt stress. Plant Mol Biol 73: 467-479.

WATANABE N, LAM E. (2008) BAX inhibitor-1 modulates endoplasmic reticulum stress-mediated programmed cell death in Arabidopsis. J Biol Chem 283: 3200-3210.

WILLIAMS B, KABBAGE M, BRITT R, DICKMAN MB. (2010) AtBAG7, an Arabidopsis Bcl-2-associated athanogene, resides in the endoplasmic reticulum and is involved in the unfolded protein response. Proc Natl Acad Sci, USA 107: 6088-6093.

YAMAMOTO K, SUZUKI N, WADA T, OKADA T, YOSHIDA H, KAUFMAN RJ, MORI K. (2008) Human HRD1 promoter carries a functional unfolded protein response element to which XBP1 but not ATF6 directly binds. J Biochem 144: 477-486.

YAN W, FRANK CL, KORTH MJ, SOPHER BL, NOVOA I, RON D, KATZE MG. (2002) Control of PERK eIF2alpha kinase activity by the endoplasmic reticulum stress-induced molecular chaperone P58IPK. Proc Natl Acad Sci, USA 99: 15920-15925.

YE J, RAWSON RB, KOMURO R, CHEN X, DAVE UP, PRYWES R, BROWN MS, GOLDSTEIN JL. (2000) ER stress induces cleavage of membranebound ATF6 by the same proteases that process SREBPs. Mol Cell 6: 1355-1364.

YOSHIDA H, MATSUI T, YAMAMOTO A, OKADA T, MORI K. (2001) XBP1 mRNA is induced by ATF6 and spliced by IRE1 in response to ER stress to produce a highly active transcription factor. Cell 107: 881-891.

ZUPPINI A, NAVAZIO L, MARIANI P. (2004) Endoplasmic reticulum stressinduced programmed cell death in soybean cells. J Cell Sci 117: 25912598 